\title{
Maltreatment and Emotional Development
}

Madeline B. Harms, Brian T. Leitzke, and Seth D. Pollak

University of Wisconsin-Madison

Department of Psychology

1202 W Johnson St

Madison, WI 53706

Corresponding author email: madeline.harms@gmail.com 


\begin{abstract}
The family environment has strong impacts on children's emotional development. Although children can adapt to a high degree of variation in the type of input they receive, child maltreatment is a species-atypical experience that disrupts the biological systems that underlie children's social and emotional development. In this chapter we describe the consequences of maltreatment on children's emotional development, focusing on alterations in 1) emotion perception, recognition, and attention, 2) emotion expression, 3) regulation of negative emotions and stress, and 4) reward processing. We consider several target mechanisms through which child maltreatment impacts these aspects of emotion processing, including behavioral, physiological, cognitive, and neurobiological, pathways. We also discuss clinical implications of this body of research, including the potential for designing effective interventions aimed at targeting specific emotional biases associated with the experience of maltreatment.
\end{abstract}




\section{Maltreatment and Emotional Development}

Child maltreatment is a widespread problem throughout the world. The Center for Disease Control (CDC) defines child maltreatment as "any act or series of acts of commission or omission by a parent or other caregiver that results in harm, potential for harm, or threat of harm to a child" (Leeb, Paulozzi, Melanson, Simon, \& Arias, 2008). Researchers who study the impact and outcomes of child maltreatment typically discuss child maltreatment in terms of acts of commission and acts of omission (Pollak et al., 2000). Acts of commission include physical, sexual, and psychological or emotional abuse, while acts of omission include failures to provide for and supervise children (e.g., neglect and exposure to violent environments).

Sub-types of maltreatment have similarly been categorized in terms of the presence of harmful input (abuse/trauma) or inadequate input (neglect/deprivation; Humphreys \& Zeanah, 2017). Subtypes of maltreatment are difficult to examine separately because children who are maltreated frequently experience more than one type of abuse (Vachon, Krueger, Rogosch, \& Cicchetti, 2015). Though there is some preliminary evidence that these subtypes of maltreatment may be associated with different emotional problems, current scientific understanding of these differential pathways is limited. Consequently, in this chapter we discuss maltreatment as a broad construct composed of these subtypes (acts of commission/harmful input and acts of omission/inadequate input) and we review research that focuses on one or more of these different components of maltreatment.

Childhood maltreatment is associated with a number of problems related to emotional development, defined as the development of emotion perception, communication, interpretation, and regulation of emotion (Halberstadt, Denham, \& Dunsmore, 2001). Abnormal development of these processes can lead to behavioral problems and psychopathology, such as post-traumatic 
stress disorder (PTSD), conduct disorder, drug addiction, delinquency, incarceration, and depression (Humphreys \& Zeanah, 2017; Cicchetti \& Ng, 2014). Critically, many of these outcomes do not become apparent until long after maltreatment has ended. This pattern suggests that childhood maltreatment might initially alter certain developmental mechanisms, such as emotion processing or response to reward and punishment, which then lead to cascading effects as development progresses. This chapter will focus on alterations in potential mechanisms of emotional development stemming from childhood maltreatment that may lead to a broad spectrum of health and behavioral problems.

\section{Emotional Problems Related to Child Maltreatment}

Childhood maltreatment is reliably associated with a broad range of negative outcomes that may stem from problems with emotion processing. For example, maltreatment is equally likely to be associated with internalizing problems like depression and anxiety symptoms, and with externalizing problems such as anger and aggressive behavior (Springer, Sheridan, Kuo, \& Carnes, 2007). Children who were maltreated also experience poorer peer relationships (Kim \& Cicchetti, 2010). This broad range of outcomes linked to maltreatment exemplifies the concept of multifinality, that similar childhood experiences can facilitate different developmental pathways due to bidirectional interactions between a child and his/her environment (Cicchetti \& Doyle, 2016). However, these diverse outcomes may share common underlying mechanisms related to emotion processing. For example, maltreated children tend to show an atypical trajectory of facial emotion recognition development, which is most apparent for expressions of anger. Relative to non-maltreated children, these children have heightened perceptual and physiological sensitivity to angry facial expressions (Pollak \& Sinha, 2002; Shackman \& Pollak, 2014), and are more likely to perceive emotional situations as demonstrating anger as early as 
preschool age (Pollak, Cichetti, Hornung, \& Reed, 2000). Studies of maltreated children also show less accurate identification of facial emotions in general (da Silva Ferreira et al., 2014; Pollak et al., 2000) and particular difficulty identifying positive emotions (Koizumi \& Takagishi, 2014). In addition, these children show abnormalities in the expression and regulation of emotions (Kim-Spoon, Cichetti, \& Rogosch, 2013). For example, physically abused children show difficulty in interpreting emotional cues, and greater tendencies to respond aggressively to conflict (Teisl \& Cicchetti, 2007), and they more commonly show contextually inappropriate expressions of emotion (Shields \& Cichetti, 1998). Another study found that 7-10-year-old physically abused boys show more aggressive behavior and negative affect than non-abused boys, and these behaviors appear to be mediated by heightened allocation of attention to angry faces (Shackman \& Pollak, 2014). Maltreated children also show higher levels of rumination (repeatedly dwelling on past negative experiences), which has been associated with an attention bias to sad faces (Romens \& Pollak, 2011) and may contribute to risk for depressive symptomatology. The combination of difficulties with emotional recognition, expression, and regulation may increase children's risk for a broad range of maladaptive outcomes. For example, misreading others' facial emotion might impair peer interactions, while problematic emotion regulation and expression may contribute to rumination and/or aggressive behavior.

There are several characteristics of maltreating families that distinguish them from typical family environments and create an atypical emotional environment for children. First, children in maltreating families that are physically abusive experience physical harm and threat from their caregivers (Bick \& Nelson, 2016; Pollak, 2015). This is in contrast to a supportive family environment, in which caregivers provide protection from physical harm. In neglectful families, caregivers fail to meet children's basic physical needs with respect to clothing, hygiene, 
food, and/or safety (Leeb et al., 2008). As a result, both neglect and abuse result in a high degree of environmental uncertainty for children: in abusive families it is difficult for a child to predict how a caregiver will react to his/her behavior, and in neglecting families, a child may not know when s/he will have food to eat or when a caregiver will be in the home. Children in maltreating families may also experience a non-normative emotional learning environment. Parents in these families often provide poor emotional signaling to their children, producing unclear facial and vocal expressions of emotion. For example, Shackman et al. (2010) found that abusive mothers produced less prototypical facial expressions of anger (i.e., less pronounced brow lowering and contracting) relative to non-abusive mothers. In addition, abusive mothers produced less prototypical vocal expressions of anger, happiness, and sadness, showing less affect and less variability between emotions than non-abusive mothers. These findings suggests that, while these parents may often be experiencing high levels of emotion, they do not convey their feelings in ways that are readily discernable or reliably predictive for their children.

These characteristics of maltreating families create pathways that lead to disturbances in children's perception, expression, and regulation of emotions. The physical harm and threat that maltreated children are exposed to results in chronic stress, which may lead to heightened anxiety, vigilance for threat, and stress dysregulation (Norman, Byambaa, Butchart, \& Vos, 2012). Unclear emotional signaling from caregivers may impair children's developing abilities to recognize and respond appropriately to the emotions of others (Kim \& Cicchetti, 2010). Finally, adverse childhood experiences such as maltreatment appear to be a from of "toxic stress" (McEwen \& Seeman, 1999) that derails healthy brain development, impacting the structural and functional development of brain regions associated with attention, emotional control, and reward learning (Hanson et al., 2015; Hart \& Rubia, 2012). Altered development of these regions is 
likely to impact many aspects of emotional development including 1) emotion perception, recognition, and attention 2) emotion expression, 3) regulation of negative emotions and stress, and 4) reward processing. Although most research to date has focused on the processing of negative emotions in the context of maltreatment, more recent research indicates that maltreatment may also alter the reward processing of reward and positive emotions. We focus on alterations in the four processes listed above and their associated neurobiology as potential mechanisms that link maltreatment to mental health and behavior problems. We also discuss the potential for interventions and therapies that target these mechanisms.

\section{Emotion Perception, Recognition, and Attentional Processes}

Children who have experienced maltreatment tend to differ from children raised in normal family environments when identifying specific emotional expressions in others. These atypical patterns of emotion recognition have implications for maltreated children's social development: emotion understanding and recognition in young children has been associated with quality of friendships, prosocial behavior, peer acceptance, and social skills later in childhood (Dunn \& Cutting, 1999; Izard et al., 2001; Mostow, Izard, Fine, \& Trentacosta, 2002). Therefore, maltreated children's atypical emotion perception and recognition patterns may partially explain their difficulties with peer relationships.

Different types of maltreatment have been associated with specific abnormalities in emotion perception and recognition. For example, children who were neglected, but not physically abused, show more difficulty in recognizing emotional expressions, perceiving fewer distinctions between emotions than either physically abused children or non-maltreated children (Pollak et al., 2000). This evidence suggests that neglected children show generalized emotion recognition deficits, possibly because parents in these families tend to express a more restricted 
range of emotions to their children, providing fewer opportunities for children to learn to associate emotional expressions with environmental events. If caregivers' emotional expressions do not reliably predict subsequent events, neglected children might begin to attend to others' emotional expressions less than typically developing children, hindering their ability to accurately recognize emotions. Physically abused children, in contrast, do not show generalized difficulties in emotion recognition. Rather, they identify anger more readily than neglected or non-maltreated children (Ardizzi et al., 2015; Briggs-Gowan et al., 2015; Cicchetti \& Curtis, 2005; Curtis \& Cicchetti, 2011; da Silva Ferreira, Crippa, \& de Lima Osório, 2014; Gibb, McGeary, \& Beevers, 2015; Pollak, Vardi, Putzer Bechner, \& Curtin, 2005; Shackman \& Pollak, 2014; Shackman, Shackman, \& Pollak, 2007). This tendency to readily and quickly recognize cues of anger and hostility is likely due to emotional attention processes that have been shaped by living in a threatening family environment.

\section{Emotional Attention Processes}

Children are exposed to an array of emotional cues and learn to direct their attention to salient and meaningful information in their environment. In an abusive family, it becomes particularly important for a child to attend to cues of anger that may indicate a threat to their well-being. This type of attention to threat cues in the environment subsequently affects the way children come to construe their social worlds. As an illustration, one study found that 5-year old abused children tended to believe that almost any kind of interpersonal situation could result in an adult becoming angry. In contrast, most non-abused children saw anger as likely to result only from particular interpersonal circumstances (Perlman, Kalish, \& Pollak, 2008). Children who suffered physical abuse are also more likely to view others as hostile and the world as generally unsafe (Gibb, 2002; Keil \& Price, 2009). These biases influence information processing, with 
physically abused children incorrectly encoding social cues and exhibiting hostile attributional biases (Teisl \& Cicchetti, 2007). Although these attentional processes reflect short-term adaptation to hostile environments, they carry long-term risk for health and behavior, contributing to problems such as aggressive behavior, depression, and anxiety.

One aspect of abused children's sensitivity to cues of anger and hostility is that they more readily identify emotional facial expressions as angry than non-maltreated children, a bias which may contribute to aggressive behavior. A series of studies demonstrate attentional biases towards angry expressions among abused children between preschool and middle childhood. For example, physically abused children more readily categorize faces that are morphed between two different emotions as angry (Pollak \& Kistler, 2002) and require less perceptual information to identify faces as angry than non-maltreated children (Pollak \& Sinha, 2002). Physically abused children also show biases to angry faces during cognitive tasks. They respond more quickly to angry faces during a Go/No-go paradigm (Pollak et al., 2001) and seem to require greater cognitive resources to disengage their attention from angry faces, showing delayed disengagement when angry faces served as invalid cues in a selective attention paradigm (Pollak \& Tolley-Schell, 2003).

Shackman \& Pollak (2014) examined individual differences in maltreated and nonmaltreated children's attention to angry faces, along with negative affect and aggression after experiencing an acute, laboratory stressor. Physically abused children showed greater negative affect after the stressor, and these negative emotions were associated with greater aggressive behavior toward children's peers. However, this association was only present among children who exhibited greater attention to angry faces. These findings demonstrate the impact of child maltreatment on emotional attention that influences children's regulation of emotion and aggression. 
Heightened attention to angry faces in abused children likely reflects vigilance for threat in the environment, and therefore may also be related to the development of anxiety disorders. Heightened vigilance to threat has been associated with anxiety disorders in children and adolescents (Krain Roy et al., 2008), suggesting that such vigilance may be a mediating factor between maltreatment and anxiety-related psychopathology. Curiously though, PTSD, one type of anxiety disorder resulting from maltreatment, has been linked to attentional biases away from angry faces during a dot probe task (Pine et al., 2005). In this case, the different task format (quickly identifying the location of a dot versus explicitly identifying an emotion) may explain the difference in findings from studies that found heightened attention towards angry faces during emotion identification. Another possibility is that maltreatment initially heightens vigilance to angry faces, but over time severely maltreated children might develop automatic tendencies to avoid angry faces, resulting in an attention bias away from threat (Krain Roy et al., 2008). What does seem clear is that individuals who experienced child maltreatment show abnormal attentional processes associated with angry expressions, which may contribute to anxiety problems.

Maltreatment-related emotional attention biases may also contribute to the development of internalizing problems such as depression. One study reported that maltreated children showed attentional biases to sad faces under certain conditions: Children who experienced high levels of maltreatment showed biased attention toward sad faces following the initiation of a sad emotional state, while maltreated children with high levels of trait rumination exhibited biased attention toward sad faces during both sad and neutral states (Romens \& Pollak, 2012). The phenomenon of rumination — a maladaptive emotion regulation strategy that involves passively and repetitively dwelling on and questioning negative feelings in response to distress - is a 
known risk factor for the development of psychopathology, particularly depression (NolenHoeksema, Wisco, \& Lyubomirsky, 2008). These cognitive patterns may identify which maltreated children are most likely to exhibit biased attention for sad cues and be at heightened risk for depression. In addition, this study illustrates how two aspects of emotion processingemotion regulation and emotional attention biases — can interact to increase maltreated children's risk for mental health problems.

\section{Neural Bases of Emotional Attention}

There is also support for alterations in regions of the brain associated with both attentional processes and emotional regulation as a result of maltreatment. The amygdala is involved in the rapid detection and response to emotionally salient events, particularly those that signal threat (Tamietto \& deGelder, 2010). While the amygdala likely plays an important role in the vigilance toward anger and hostility observed in maltreated children, this is not the amygdala's only role. In addition to modulation by the frontal cortex (e.g., during emotion regulation), there is strong evidence that the amygdala coordinates the function of cortical networks when an organism evaluates the biological significance of affective information (for review, see Pessoa \& Adolphs, 2010). In this way, the amygdala may influence higher-level cortical processing of emotional events, indicating that it can influence attention and appraisal of information both early and late in the processing stream.

In some, but not all, maltreated samples, the amygdala region shows abnormal development. For example, Hanson et al. (2015) completed rigorous hand tracing of the amygdala in samples of children who experienced different forms of early stress including physical abuse, early neglect, or extreme family poverty. They found smaller amygdala volumes for children exposed to these different forms of stress. Furthermore, amygdala volumes were 
associated with both greater cumulative stress exposure and a higher prevalence of child behavioral problems (Hanson et al., 2015). These data suggest that early and severe life stress may be associated with increased excitation and cell death, reflected in reductions in gray matter volume. Although smaller, the amygdala may become overactive in maltreated children, who tend to show a heightened response in the amygdala during emotion processing tasks (Dannlowski et al., 2012; McCory et al., 2011, 2013; McLaughlin, Peverill, Gold, Alves \& Sheridan, 2015; van Harmelen et al., 2013). Structural and functional alterations in the amygdala may help us understand individual differences in risk and resilience to behavioral problems as related to toxic stress.

\section{Interventions Targeting Emotional Attention}

These emotional attention disturbances in maltreated children may also hold promise as targets for intervention. One example is the proliferation of attention bias modification paradigms that have been used to alter emotional attention biases associated with psychopathology (Shechner et al., 2011). Effective behavioral methods have been developed to ameliorate symptoms in a range of mental health problems including anxiety (Amir, Beard, Burns, \& Bomyea, 2009), depression (Beevers, Clasen, Enoch, \& Schnyer, 2015), phobias (Amir, Taylor, \& Donohue, 2011), disordered eating (Renwick, Campbell, \& Schmidt, 2013), and substance abuse (Field, Duke, Tyler, \& Schoenmakers, 2009). Existing interventions that target attentional processes have most commonly been designed to reduce or modify maladaptive attention toward disorder-relevant stimuli (e.g., threat; Mogg, Waters, \& Bradley, 2017). A number of training programs have been developed, with the most common being a modified versions of visual probe, or "Dot Probe" task (MacLeod, Rutherford, Campbell, Ebsworthy, \& Holker, 2002), which promotes threat avoidance (e.g., Amir, Beard, Burns, \& Bomyea, 2009). 
The modified visual probe task is based on research implicating preferential attention toward certain stimuli as a contributing factor in the development and maintenance of behavioral and mental health difficulties (Shechner \& Bar-Haim, 2016). This task was designed to promote avoidance of threat-related cues by requiring participants to respond to a probe that appears behind a neutral stimulus a greater proportion of time than a targeted, threat-related stimulus. This training paradigm allows participants to learn the probable location of the probe and thus where to attend to improve their performance. In this way, participants learn to preferentially attend away from target cues in favor of the reinforced neutral cues (Bar-Haim, 2010). Such training programs have demonstrated alterations in attentional biases as well as reductions in various psychological symptoms (Beevers, Clasen, Enock, \& Schnyer, 2015; Linetzky, Pergamin-Hight, Pine, \& Bar-Haim, 2015; Mogoaşe, David \& Koster, 2014; Pergamin-Hight, Naim, Bakermans-Kranenburg, Van Ijzendoorn, \& Bar-Haim, 2015; Shechner \& Bar-Haim, 2016).

An alternative training program, interpretation bias training, was designed to improve the ability to discriminate between different emotions (Penton-Voak, Bate, Lewis, \& Munafo, 2012). In this task, participants view single facial expressions of emotion morphed from one high intensity emotion to another (e.g., anger to happiness) and then attempt to identify what emotion is being expressed. To improve discriminability, participants receive corrective feedback during the training portion of the task. Such training is designed to alter individuals' interpretation of ambiguous faces to be more happy, and less threatening (Penton-Voak, Bate, Lewis, \& Munafo, 2012; Penton-Voak et al., 2013; Stoddard et al., 2016). This paradigm has yielded shifts in maladaptive attentional tendencies as well as improvements in problematic symptomatology, 
including aggression and irritability in adolescent samples (Penton-Voak, Bate, Lewis, \& Munafo, 2012; Stoddard et al., 2016).

While not geared toward the specific deficits associated with a history of maltreatment, these advances suggest that similar types of approaches--if appropriately tailored--may also help address the threat biases and concomitant behavioral problems among maltreated children. Promoting avoidance of threat, such as in the modified visual probe task, may in fact prove maladaptive for maltreated children, as the ability to quickly identify threat in a potentially dangerous situation allows for a possible escape from harm. However, improving children's ability to more accurately recognize certain emotional cues, such as anger, may prove adaptive if generalized to more social, non-threatening environments. A training program that improved accuracy in recognizing emotional cues may have the added benefit of maintaining the ability to recognize threat in settings where such cues are indicative of probable harm. Furthermore, interventions that successfully reduce maltreated children's hypervigilance to threat and hostility in others may reduce these children's own experience and expression of negative emotions.

\section{Emotional Expression}

The unpredictable and disorganized qualities that are associated with maltreating families - including unclear emotional signaling and inconsistent reactions to children's behavior--are likely to alter children's experience and expression of emotions, in addition to their emotion recognition and perception. In contrast to emotion perception and recognition, little is known about the extent to which abuse versus neglect exerts differential influences on children's emotional expression; most research to date on this topic involves children who were physically abused or who experienced a combination of abuse and neglect. Children living in these environments are likely to experience frequent negative emotions, including anger, frustration, and irritability (Shields \& Cicchetti, 1998). Indeed, maltreated children show higher levels of 
negative emotionality than non-maltreated children particularly in terms of anger reactivity (Gunnar \& Donzella, 2002). In addition to a preponderance of negative emotions, these children may be vulnerable to overwhelming emotional arousal. Such chronically heightened arousal may lead to difficulties managing and regulating intense emotions such as anger (Cummings, Hennessy, Rabideau, \& Cicchetti, 1994). The proclivity to experience intense negative emotions combined with high emotional arousal may explain the tendencies of maltreated children to experience anger and behave aggressively in challenging social situations.

One aspect of emotional expression that has been studied in the context of child maltreatment is emotion lability/negativity, described as children's speed in reacting to affective stimuli and difficulty in recovering from negative emotional reactions (Dunsmore, Booker, \& Ollendick, 2011). As an illustration, a child with high emotion lability/negativity may be prone to angry outbursts or exhibit dramatic mood swings. A longitudinal study of maltreated and nonmaltreated children (Kim-Spoon, Cicchetti, \& Rogosch, 2013) showed that maltreatment predicted higher emotion lability/negativity. Furthermore, lower levels of emotion regulation and higher levels of emotion lability/negativity were independently associated with increases in internalizing symptomatology between eight and nine years of age. In addition, emotion regulation mediated the longitudinal link between emotion lability/negativity and change in internalizing symptomatology among both groups of children: those with high emotion lability/negativity showed poor emotion regulation in the following year, which in turn predicted an increase in internalizing symptomatology. This study suggests that high emotion lability/negativity might interfere with the development of effective emotion regulatory strategies.

In a maltreating environment, children's heightened frequency and intensity of negative emotions likely requires greater emotion regulation capacity to manage. At the same time, Kim- 
Spoon et al (2013) report that maltreatment appears to derail children's development of emotion regulation skills. Thus, a maltreated child is likely to experience intense negative emotions and to lack the skills and strategies need to regulate them in the service of goal-directed behavior. Insufficient regulation and management of emotions may lead to circumstances in which children are frequently overwhelmed by negative emotions, and in turn contribute to the development of internalizing symptomatology (Calkins \& Fox, 2002; Cicchetti \& Toth, 1998). These interactions between emotional reactivity/expression and emotion regulation are an important potential mechanism underlying the development of internalizing disorders in maltreated children.

\section{Emotion Regulation}

Problems with emotion regulation are some of the most commonly noted sequelae of childhood maltreatment. Emotion regulation refers to an individual's ability to modify his/her own emotional arousal in order to maintain an optimal level of engagement with the environment (Thompson, 1994). Thus, emotion regulation is intertwined with emotional reactivity, and these two constructs are often difficult to disentangle. Emotion regulation allows children to respond in flexible and socially appropriate ways to changing demands in the environment (e.g., it may be acceptable to express dismay with a disappointing gift in some circumstances, but typically not when in the presence of the gift giver). Poor emotion regulation abilities are reflected in a broad range of negative outcomes, including internalizing problems (Kim \& Cicchetti, 2010), externalizing problems (Herts, McLaughlin, \& Hatzenbuehler, 2012), and peer rejection (Hanish et al., 2004). All of these problems are more prevalent in maltreated children relative to the general population, and are associated with psychopathological problems including depression, anxiety, and conduct disorder. 
There is strong evidence that emotion regulation mediates links between maltreatment and later mental health and behavior problems. For example, one study found that young adults who experienced maltreatment as children showed higher levels of ADHD symptoms than nonmaltreated individuals. However, this relation was mediated by individual differences in coping self-efficacy, an aspect of emotion regulation defined as the belief that one can effectively utilize coping behaviors in stressful situations. Maltreated individuals with high coping self-efficacy showed lower ADHD symptoms than those with low coping self-efficacy (Singer, Humphreys, \& Lee, 2016). In addition, in a longitudinal study of over 400 children 6-12 years of age, Kim and Cicchetti (2010) found that neglect, physical abuse, and sexual abuse all predicted emotion dysregulation in early childhood, which in turn predicted peer rejection and externalizing symptoms in later childhood. These studies raise the possibility that diminished emotion regulation resulting from childhood maltreatment may lead to a cascade of social problems that ultimately result in increased risk for psychopathology and behavioral problems.

There is also evidence that the timing of maltreatment influences relationships between emotion regulation and subsequent mental health problems. Emotion regulation may be a stronger predictor of subsequent internalizing symptomatology in early childhood than in later childhood because younger children have not yet developed the cognitive and social skills that help older children cope with stress (Cole, Luby, \& Sullivan, 2008). For the same reason, younger children, who are just beginning to develop abilities to regulate their emotions, may be more vulnerable to environmental stress such as maltreatment. Maltreatment in early childhood may both hinder the emergence of emotion regulation skills (Kim-Spoon et al., 2013), and in turn prevent the development of higher-level executive function capacities that build upon this initial regulatory capacity. This notion may explain why maltreatment occurring in early childhood 
appears to exert more deleterious effects on mental health and social adjustment than maltreatment that is confined to later childhood or adolescence (Pechtel \& Pizzagalli, 2011). Neural Bases for Emotion Regulation

Emotion regulation is dependent on the prefrontal cortex (PFC) and its connections with limbic brain regions involved in emotional reactivity. During emotional events, an optimally functioning PFC can modulate the activity of limbic brain regions to keep emotional reactivity at an appropriate level. For example, when individuals are instructed to regulate negative emotions using cognitive reappraisal, PFC activity reduces negative emotion by increasing activity in limbic regions involved in the generation of positive emotions (i.e., ventral striatum/nucleus accumbens) and decreasing activity in regions involved in generating negative emotions (i.e., amygdala). The modulation of these systems implicated in affective appraisal and learning processes in turn impacts individuals' emotional experience (Wager et al., 2008). The PFC is significantly impacted by childhood maltreatment and other forms of early adversity (Hart \& Rubia, 2012), likely because it contains a high density of glucocorticoid receptors; therefore, chronically high levels of stress hormones disproportionately interfere with the growth and development of the PFC (Joels et al., 2007; Dias-Ferreira et al., 2009). Smaller PFC gray matter volumes are commonly observed in individuals exposed to childhood maltreatment (Gorka, Hanson, Radtke, \& Hariri, 2012; Hanson et al., 2010). Although links between brain structure and function are not always straightforward, a reduction in the number of PFC neurons and/or dendrites might impair the PFC's ability to regulate the activity of limbic brain regions. Supporting this notion, childhood maltreatment is also associated with weakened functional connectivity between the ventral PFC and subcortical regions such as the amygdala and hippocampus. This reduced connectivity may play a role in fear regulation and contribute to the 
development of PTSD (Birn, Partriat, Phillips, Germain, \& Herringa, 2014). Another recent study found that childhood maltreatment was associated with reduced structural integrity of the uncinate fasciculus (UF) in young adults, a major white matter tract that links the ventromedial PFC to the amygdala (Hanson et al., 2015). Structural integrity of the UF also mediated the relationship between childhood maltreatment and internalizing symptoms assessed at a later time point, with lower UF integrity predicting higher internalizing symptoms. This relation suggests a potential causal link between a neural pathway involved in emotion regulation and mental health.

Abnormal growth and development of brain regions that regulate stress and negative emotions may influence subsequent mental health by hindering the ability to regulate stress responses to later events. If an individual cannot efficiently regulate his emotions during stressful situations, those stressors are more likely to adversely affect their psychological functioning. Supporting this idea, Hanson et al. (2015) found that the link between UF integrity and internalizing problems was most pronounced in individuals who experienced additional stressful events between their initial scan and later psychological assessment. Individuals who had greater stress exposure over the course of the study showed a stronger negative correlation between UF integrity and internalizing symptoms. Another study (Gorka et al., 2012) found that reduced gray matter volume in the hippocampus and medial prefrontal cortex regions mediated the association between self-reported childhood maltreatment and trait anxiety in adulthood and predicted the association between anxiety symptoms and stressful life events in the subsequent year. These results suggest that reduced volume in these regions is associated with higher susceptibility to future stressful events.

\section{Hormonal Regulation of Emotions and Stress}

Additional evidence that increased biological and psychological reactivity to later life 
stressors could mediate links between childhood maltreatment and mental health outcomes comes from studies examining the regulation of stress by the hypothalamic-pituitary-adrenal (HPA) axis. This system also plays an important role in emotion regulation. When an individual encounters a stressor, corticotropin-releasing hormone $(\mathrm{CRH})$ is secreted from the hypothalamus. This hormone acts on the pituitary gland, causing it to release adrenocorticotropic hormone (ACTH). ACTH then acts upon the adrenal gland, resulting in the production of cortisol. Cortisol binds with glucocorticoid (GR) receptors in the hippocampus to regulate the HPA axis and inhibit further release of CRH. Similarly, cortisol released in response to stress binds with GR receptors at the cellular level to regulate the immune system (Lupien, McEwen, Gunnar, \& Heim, 2009).

The HPA axis promotes adaptation in response to normative stressors. However, toxic or extreme levels of early life stress exposure, such as severe maltreatment, may impair biological regulation of stress hormones, as well as general health and immune functioning (Koss, Hostinar, Donzella, \& Gunnar, 2014). For example, in typically developing individuals, cortisol release follows a diurnal rhythm with higher levels in the morning and lower levels in the evening. However, this diurnal pattern may be altered in children exposed to severe early life stress. A recent meta-analysis showed that maltreatment was strongly associated with lower awakening cortisol levels (Bernard, Frost, Bennet, \& Lindheim, 2017). In addition, a review of 20 studies examining stress and adult immune function found that child maltreatment was reliably associated with higher levels of circulating inflammatory proteins in adulthood (Coelho et al., 2013) pointing to long-term health effects of this type of chronic stress.

Altered functioning of HPA systems may help to explain relationships between child maltreatment and behavior problems. For example, one study found that children who had been 
abused and exhibited abnormal, flat diurnal cortisol rhythms tended to exhibit high levels of aggressive behaviors (Bernard, Zwerling, \& Dozier, 2015). However, children with normal diurnal cortisol rhythms did not show increased aggressive behavior. These findings suggest a relation between maltreatment and dysregulated stress reactivity that may have implications for the development of emotion regulation. Along these lines, dysregulation in stress reactivity was found to mediate the relation between child maltreatment and the later emergence of externalizing behaviors in a longitudinal study spanning from middle to high school, with greater stress dysregulation predicting more externalizing problems (Heleniak, Jenness, Vander Stoep, McCauley, \& McLaughlin, 2015). Causal influences between cortisol reactivity and emotion regulation may operate in both directions. Abnormal diurnal cortisol patterns may diminish children's ability to regulate their emotions, but emotion regulation can also influence the appraisal of stressful situations and halt or modulate the stress response (Stansbury \& Gunnar, 1994).

\section{Prevention and Intervention for Emotion Regulation Difficulties}

In sum, maltreatment appears to disrupt the development of neurobiology that facilitates emotion regulation, which can contribute to both internalizing and externalizing problems later in development. However, emotion regulation is a promising target for therapy-based approaches to aid emotional development in victims of maltreatment. For example, trauma-focused cognitive behavior therapy is a treatment for traumatized children that provides individual and family therapy and includes parental or caregiver participation as a critical component (Cohen \& Mannarino, 2015). Trauma-focused cognitive behavior therapy provides psychoeducation, targets emotion regulation and cognitive processing, and has strong empirical support for improving symptoms of anxiety, depression, and PTSD in addition to behavioral, cognitive, and 
relationship problems for both children and parents. Despite these promising developments, to fully address emotion-processing sequelae of maltreatment and prevent psychopathology, interventions that target positive emotions and reward, in addition to management of negative emotions, may be needed in light of recent evidence that maltreatment appears to disrupt reward processing.

\section{Reward Processing}

Most research to date has focused on how maltreated children perceive, recognize, and respond to negative emotions, given the preponderance of negative emotions to which these children are exposed. However, there is a growing scientific interest and awareness in the effects of early stressful environments on children's processing of positive emotional information in the form of rewards. Rewards consist of positively valenced events or information that tend to elicit approach and/or consumnatory behavior. As shown by animal and human research, rewards also facilitate learning, i.e. associating events or behaviors with rewarding or non-rewarding information (Schoenbaum \& Roesch, 2005). After repeated associations involving reward, individuals learn to repeat actions that result in reward and cease actions that result in nonreward or punishment. In addition, rewards tend to induce positive emotions such as excitement and satisfaction (Berridge, Robinson, \& Aldridge, 2009). Reward processing thus provides a useful window into understanding the multiple levels of impact that child maltreatment may have on emotional development.

Abnormal responsivity to rewarding information might help to explain several difficulties that have been noted in maltreated individuals. One commonly observed phenomenon is anhedonia, a lack of positive emotion that is thought to be an endophenotype of depression 
(Pizzagalli, 2014). Individuals with anhedonia may not take pleasure in stimuli or activities that are typically experienced as rewarding, such as food or social activities. Another problem that has been observed in maltreated adolescents and adults is difficulty learning from positive and negative feedback (Hanson et al., 2017: Harms, Shannon Bowen, Hanson, \& Pollak, 2017; Pechtel \& Pizzagalli, 2013). In probabilistic or instrumental learning tasks, abused individuals are slower to associate images with positive or negative feedback than non-maltreated children, as reflected in their accuracy in selecting the image that is associated with reward. Attention to and engagement with rewarding information is necessary both to take pleasure in rewards and to use rewards to guide future behavior. Hypo-responsivity to rewarding information might therefore explain why maltreatment is associated with both anhedonia and associative learning difficulties.

In contrast to heightened attention toward negative or threatening information exhibited by maltreated children, a growing body of evidence shows a relation between maltreatment and reduced reactivity to the anticipation and/or consumption of reward. Because reward processing in the context of maltreatment is a relatively new area of research, little is known about whether different forms of maltreatment are associated with different reward-related processes. Nevertheless, there is evidence that children exposed to various forms of maltreatment prioritize negative cues at the expense of positive cues. For example, when viewing emotional facial expressions, abused children identified as having attachment anxiety exhibit an attentional bias away from facial expressions depicting happiness (Davis, Fani, Ressler, Jovanovic, Tone, \& Bradley, 2014). Consistent with this view, on a probabilistic reward task, maltreated children fail to show sensitivity to important environmental cues, such as changing rewards (Guyer et al., 2006; Mueller et al., 2012; Weller \& Fisher, 2013). In contrast, non-maltreated children respond 
more quickly as their chances of winning a reward increase. Reports of primate behavior also suggest that maltreated monkeys display less interest in rewards relative to control monkeys (Pryce, Dettling, Spengler, Schnell, \& Feldon, 2004). While these findings emphasize the importance of early experience in shaping responses to rewards, a greater understanding of the brain regions associated with learning reward or punishment is likely to help account for the effects of the environment on maltreated children's interpersonal behavior. Indeed, a few candidate brain systems have emerged as potentially underlying these phenomena and provide clues about the development of psychopathology.

\section{Neural Mechanisms of Reward Processing}

Rodent studies provided the first pieces of information regarding links between abnormal parenting behaviors and offspring's reward processing. For example, experimental disruption of reward circuitry in the brain prevents mice pups from emitting vocalizations when removed from their mothers; such a disturbance interferes with brain reward systems and also prevents mice from showing a preference for their own mothers (Moles, Kieffer, \& D'Amato, 2004). This association also works in the opposite direction: when attachment to the parent is disrupted, other aspects of the animals' reward systems are affected. Animals with disrupted attachments to their parents also show abnormal responses to novelty, altered appetitive conditioning, and unusually high sensitivity to dopamine antagonists and reactivity to other drug administrations. This cluster of symptoms resembles anhedonia, which is a symptom of depression in humans (for review, see Bakermans-Kranenburg \& Van Ijzendoorn, 2011; Matthews \& Robbins, 2003).

The brain region most often associated with reward processing is the ventral striatum (VS), which is part of the basal ganglia, a diverse network of subcortical structures that work in concert to orchestrate and execute planned, motivated behaviors that require integration of 
movement, thinking, and feeling (Haber, 2003). Adolescents and adults exposed to childhood family adversity and maltreatment tend to show decreased VS response during reward anticipation (Boecker et al., 2014; Dillon et al., 2009; Hanson et al., 2016; Holtz et al., 2016). Interestingly, these populations do not show blunted VS activity when they actually receive a reward, suggesting that these types of early adversity might particularly influence the ability to learn rewarding-predicting cues. Blunted VS activity during reward anticipation might also reflect deficits in approach behavior toward biologically relevant goals, which may result in less effort and motivation to obtain rewards (Holtz et al., 2016). This pattern would have adverse affects for social functioning, which is dependent on the desire to obtain rewards such as social approval.

The anterior cingulate cortex (ACC) is another area of the frontal cortex implicated in reward learning. Computational models, single-unit recording in non-human animals, studies of human patients with brain damage, and basic cognitive neuroscience studies in typically developing humans all cohere in suggesting that the ACC plays a central role in how organisms make predictions and improve those predictions by processing prediction errors (Botvinick, Cohen, \& Carter, 2004; Ridderinkhof, 2004; Schultz \& Dickinson, 2000). Prediction errors are engines of learning because detecting differences in outcomes guides subsequent actions.

Neuronal loss and smaller volumes in the ACC have been reported in children who have suffered physical abuse compared to non-maltreated children (Carrion et al., 2009; De Bellis, Keshavan, Spencer, \& Hall, 2000; Teicher, Anderson, Ohashi \& Polcari, 2014; Thomaes, Dorrepaal, \& Draijer, 2010). Hanson and colleagues (Hanson et al., 2012) found that children who experienced high levels of early life stress had smaller volumes in the ACC and also more errors during an executive functioning task. In that study, individual differences in ACC volumes 
accounted for the association between levels of early life stress and the number of errors children made during the task. Research in non-human animals has also noted structural differences in the ACC, with lower dendritic branching in this area in rodents exposed to early stress (Gos, Bock, Poeggel, \& Braun, 2008).

Functional brain imaging has also revealed that abused adolescents who showed lower ACC activation to reward trials during reversal learning performed more poorly on the task. This finding could reflect reduced cognitive engagement during rewarded trials in adolescents who had difficulty switching associations (Harms et al., 2017). Similarly, resting-state functional connectivity points to effects of child maltreatment in the circuit level dynamics of the ACC related to abuse (Herringa, Birn, \& Ruttle, 2013). Taken together, these findings are consistent with the possibility that children who have suffered from maltreatment experience problems related to associative learning processes. Reduced engagement and attention to reward as reflected in ACC activity may lead to reduced learning from reward. Such processes may lead to a cascade of developmental challenges because they are a major component of adaptive social learning. In this manner, learning difficulties may undermine children's attempts to develop effective strategies to cope with changing environmental contingencies.

The orbito-frontal cortex (OFC) is another region that plays an important role in reward processing. The OFC is is crucial for signaling and updating outcome expectancies such as reward/punishment to facilitate associative learning (Kringelbach \& Rolls, 2004). This region also contributes to an organism's ability to flexibly adapt behavior in response to changing contingencies (Murray, O'Doherty, \& Schoenbaum, 2007), in coordination with the basal ganglia (Frank \& Claus, 2006). Interestingly, OFC neurons do not stop firing in response to a reward after learning, suggesting that these neurons support predictions on the basis of afferent input and 
anticipation prior to other emotion-processing regions such as the amygdala (Schoenbaum, Roesch, Stalnaker, \& Takahashi, 2009). As expected, impairments in these systems are associated with poor learning from environmental cues.

Supporting the role of the OFC in reward learning, damage to the OFC causes deficits in reversal learning, reduces the speed of reward learning, and is activated in humans during processes such as regret and counterfactual reasoning (Honey, Kötter, \& Breakspear, 2007; Passingham, Stephan, \& Kötter, 2002). Common to these examples is the need to signal, in realtime, information about outcomes predicted by circumstances in the environment. Some emerging evidence suggests functional changes in the OFC and BG during reward processing in adolescents (Galvan et al., 2006). This further suggests that these systems are a source of developmental changes in social behavior.

There is some inconsistency in the literature regarding the effects of maltreatment on the structure and function of the orbitofrontal cortex (OFC). There have been reports of both smaller volumes (Hanson et al., 2010; Holz et al., 2015; McCrory, De Brito, \& Viding, 2012) and larger volumes (Carrion et al., 2009) in the OFC for children and adolescents who have suffered physical abuse. Inconsistencies have also been found in non-human animals, with both dendritic expansion (Liston et al., 2006) and retraction (Helmeke et al., 2009) reported in the OFC after chronic stress exposure. Functional brain imaging may help in clarifying the role of frontal lobe circuitry in developmental problems associated with maltreatment. However, functional abnormalities in the OFC have not consistently been identified among maltreated individuals. Although abnormal structure and function of the VS and ACC have been associated with maltreatment, links between maltreatment and abnormal reward processing might be a function of network-level and connectivity disturbances, rather than abnormal size or function of 
individual regions. This would not be surprising, given that reward pathways involve the complex coordination of many brain regions (Haber \& Knutson, 2010).

There is evidence that functioning of these reward systems may account, in part, for how child maltreatment confers pervasive lifetime risks for children, but also confers the potential for resilience. As an illustration, hypoactive reward processing has repeatedly been demonstrated in depression (Pizzagalli, 2014; Russo \& Nestler, 2013), and a substantial portion of depressed individuals have a history of maltreatment (Norman et al., 2012). This suggests that maltreatment may confer risk for depression via hypoactive reward processing. However, behavioral and neural reward reactivity during a monetary-incentive delay task has been shown to moderate the association of maltreatment with depression. Both faster reaction times to cues that predicted monetary reward and greater activation of the left pallidum, a region of the basal ganglia, were linked to lower symptoms of depression in maltreated adolescents (Dennison et al., 2016). Furthermore, higher levels of reward response predicted lower increases in depression over the next two years. This study suggests that higher reactivity to monetary reward is a potential marker of resilience to depression among adolescents exposed to maltreatment. Future interventions could capitalize on findings such as this one to develop treatments that increase attention to and processing of reward cues in children exposed to maltreatment.

\section{Conclusions and Future Directions}

Although it has been clear for a number of years that maltreatment in the family tends to result in disturbances in children's emotional development, the mechanisms that explain these processes are not fully understood. Here, we focused on emotion and stress regulation, the perception and expression of emotion, and reward processing as critical components linking child maltreatment to difficulties in emotion processing and development. Each of these 
mechanisms has been empirically shown to link child maltreatment to later mental health problems. However, there are undoubtedly additional mechanisms that will be uncovered by future research.

There are some outstanding limitations in the current literature that, if addressed, will greatly improve our understanding of the specific impacts of child maltreatment on emotional development. First, many studies still rely on self-report by adult subjects of past maltreatment. This approach may not accurately capture specific aspects of timing and chronicity of maltreatment, which are important factors in emotional development. For example, some studies indicate that children who were abused earlier and more chronically show more maladaptive emotional and cognitive processes (Cowell, Cicchetti, Rogosch,\& Toth, 2015; Pechtel \& Pizzagall, 2011), and higher rates of anxiety and depression (Kaplow \& Widom, 2007). Studying the sequelae of child maltreatment is also complicated by the fact that many of the emotional manifestations of this early stress do not appear until much later in development, often adolescence or even adulthood. For example, adolescents in substance abuse treatment who were maltreated in early childhood are more likely to relapse than adolescents who were not maltreated, and relapse appears to be linked to maltreatment-related changes in limbic brain regions (Van Dam et al., 2012). Long-term alterations in limbic brain regions (Dannlowski et al., 2012) and HPA system function (Gunnar \& Quevedo, 2008) due to maltreatment may also contribute to other problems that tend to emerge during adolescence, such as depression and PTSD. Adolescence may represent an especially vulnerable time for maltreated individuals due to changes in fronto-limbic connectivity patterns that occur during the pubertal transition (Ladouceur, 2012). Despite evidence of these sleeper effects, there are few longitudinal studies that identify maltreatment in childhood and observe emotional development in these individuals 
until adulthood. These types of studies are essential to understanding how maltreatment impacts emotion processing and how certain developmental mechanisms confer mental health risks over time. The few longitudinal studies that do exist suggest that maltreatment in infancy and/or early childhood may be associated with the most significant emotional and neurocognitive problems across development (Cowell et al., 2015; Kim-Spoon, Cicchetti, \& Rogosch, 2013). Yet, psychopathologies such as depression, conduct disorder, and drug abuse are often not apparent until adolescence. Long-term longitudinal studies are thus essential to improve our understanding of links between maltreatment, emotional development, and mental health.

A final limitation in understanding the effects of child maltreatment on the development of emotion systems is that maltreatment history is likely to reflect the potential for broader stress and conflict in family relationships (Kim-Spoon, Cicchetti, \& Rogosch, 2013). Factors in the family environment such as parenting behaviors, marital relationships, and communication of positive and negative emotion among family members also impact children's emotional development (Morris et al., 2007), and their effects may be difficult to tease apart from those of maltreatment. Thus, future research that examines the unique effects of these other aspects of the emotional climate within maltreating and non-maltreating families will benefit the field. 
Amir, N., Beard, C., Burns, M., \& Bomyea, J. (2009). Attention modification program in individuals with generalized anxiety disorder. Journal of Abnormal Psychology, 118(1), 28-33. http://doi.org/10.1037/a0012589

Amir, N., Taylor, C. T., \& Donohue, M. C. (2011). Predictors of response to an attention modification program in generalized social phobia. Journal of Consulting and Clinical Psychology, 79(4), 533-541. http://doi.org/10.1037/a0023808

Ardizzi, M., Martini, F., Umiltà, M. A., Evangelista, V., Ravera, R., \& Gallese, V. (2015). Impact of childhood maltreatment on the recognition of facial expressions of emotions. PloS One, 10(10), e0141732-19. http://doi.org/10.1371/journal.pone.0141732

Bakermans-Kranenburg, M. J., \& Van Ijzendoorn, M. H. (2011). Differential susceptibility to rearing environment depending on dopamine-related genes: New evidence and a metaanalysis. Development and Psychopathology, 23(01), 39-52. http://doi.org/10.1017/S0954579410000635

Beevers, C. G., Clasen, P. C., Enoch, P. M., \& Schnyer, D. M. (2015). Attention bias modification for major depressive disorder: Effects on attention bias, resting state connectivity, and symptom change. Journal of Abnormal Psychology, 124(3), 463-475. http://doi.org/10.1037/abn0000049

Bernard, K., Zwerling, J., \& Dozier, M. (2015). Effects of early adversity on young children's diurnal cortisol rhythms and externalizing behavior. Developmental Psychobiology, 57(8), 935-947. http://doi.org/10.1002/dev.21324

Bick, J., \& Nelson, C. A. (2016). Early adverse experiences and the developing brain. Neuropsychopharmacology, 41(1): 177-196. doi: 10.1038/npp.2015.252 
Bigelow, A. E., \& DeCoste, C. (2003). Sensitivity to social contingency from mothers and strangers in 2-, 4-, and 6-month-old infants. Infancy, 4(1), 111-140. http://doi.org/10.1207/S15327078IN0401_6

Birn, R. M., Patriat, R., Phillips, M. L., Germain, A., \& Herringa, R. J. (2014). Childhood maltreatment and combat posttraumatic stress differentially predict fear-related frontosubcortical connectivity. Depression and Anxiety, 31(10), 880-892. http://doi.org/10.1002/da.22291

Botvinick, M. M., Cohen, J. D., \& Carter, C. S. (2004). Conflict monitoring and anterior cingulate cortex: An update. Trends in Cognitive Sciences, 8(12), 539-546. http://doi.org/10.1016/j.tics.2004.10.003

Bousha, D. M., \& Twentyman, C. T. (1984). Mother-child interactional style in abuse, neglect, and control groups: Naturalistic observations in the home. Journal of Abnormal Psychology. http://doi.org/10.1037/0021-843X.93.1.106

Briggs-Gowan, M. J., Pollak, S. D., Grasso, D., Voss, J., Mian, N. D., Zobel, E., ... Pine, D.S. (2015). Attention bias and anxiety in young children exposed to family violence. Journal of Child Psychology and Psychiatry, 56(11), 1194-1201. http://doi.org/10.1111/jcpp.12397

Burgess, K. B., Wojslawowicz, J. C., Rubin, K. H., Rose-Krasnor, L., \& Booth-LaForce, C. (2006). Social information processing and coping strategies of shy/withdrawn and aggressive children: Does friendship matter? Child Development, 77(2), 371-383. http://doi.org/10.1111/j.1467-8624.2006.00876.x

Call, J. (2001). Chimpanzee social cognition. Trends in Cognitive Sciences, 5(9), 388-393. http://doi.org/10.1016/S1364-6613(00)01728-9 
Capitanio, J. P. (1984). Early experience and social processes in Rhesus macaques (Macaca Mulatta): I. Dyadic social interaction. Journal of Comparative Psychology, 98(1), 35. http://doi.org/10.1037/0735-7036.98.1.35

Carrion, V. G., Weems, C. F., Watson, C., Eliez, S., Menon, V., \& Reiss, A. L. (2009). Converging evidence for abnormalities of the prefrontal cortex and evaluation of midsagittal structures in pediatric posttraumatic stress disorder: An MRI study. Psychiatry Research: Neuroimaging, 172(3), 226-234. http://doi.org/10.1016/j.pscychresns.2008.07.008

Champagne, F. A., \& Curley, J. P. (2011). Epigenetic influence of the social environment. In Brain, Behavior and Epigenetics (pp. 185-208). Berlin, Heidelberg: Springer Berlin Heidelberg. http://doi.org/10.1007/978-3-642-17426-1_10

Cicchetti, D., \& Curtis, W. (2005). An event-related potential study of the processing of affective facial expressions in young children who experienced maltreatment during the first year of life. Development and Psychopathology, 17(03), 641-677. http://doi.org/10.1017/S0954579405050315

Cicchett, D., \& Doyle, C. (2016). Child maltreatment, attachment, and psychopathology: mediating relations. World Psychiatry, 15, 89-90. doi: 10.1002/wps.20337

Cohen, J. A. \& Mannarino, A. P. (2015). Trauma-focused cognitive behavior therapy for traumatized children and families. Child Adolescent Psychiatric Clinics of North America, 24(3), 557-570. http://doi.org/10.1016/j.chc.2015.02.005

Cohen, J. A., Scheid, J., \& Gerson, R. (2014). Transforming trajectories for traumatized children. Journal of the American Academy of Child and Adolescent Psychiatry, 53(1), 9-13. http://doi.org/10.1016/j.jaac.2013.10.004 
Cowell, R. A., Cicchetti, D., Rogosch, F. A., \& Toth, S. L. (2015). Childhood maltreatment and its effect on neurocognitive functioning: Timing and chronicity matter. Development and Psychopathology, 27(02), 521-533. http://doi.org/10.1017/S0954579415000139

Cummings EM, Hennessy K, Rabideau G, Cicchetti D. Responses of physically abused boys to interadult anger involving their mothers. Development and Psychopathology. 1994;6:31-42. doi:10.1017/S0954579400005861.

Dunsmore JC, Booker JA, Ollendick TH. Parental emotion coaching and child emotion regulation as protective factors for children with oppositional defiant disorder. 2011.

Curtis, W. J., \& Cicchetti, D. (2011). Affective facial expression processing in young children who have experienced maltreatment during the first year of life: An event-related potential study. Development and Psychopathology, 23(02), 373-395. http://doi.org/10.1017/S0954579411000125

da Silva Ferreira, G. C., Crippa, J. A. S., \& de Lima Osório, F. (2014). Facial emotion processing and recognition among maltreated children: A systematic literature review. Frontiers in Psychology, 5. http://doi.org/10.3389/fpsyg.2014.01460/abstract

Danese, A. (2014). Developmental psychoneuroimmunology: From bench to bedside. Brain Behavior and Immunity, 36(C), 27-28. http://doi.org/10.1016/j.bbi.2013.11.001

Danese, A., Moffitt, T. E., Harrington, H., Milne, B. J., Polanczyk, G., Pariante, C. M., ... Caspi, A. (2009). Adverse childhood experiences and adult risk factors for age-related disease. Archives of Pediatrics \& Adolescent Medicine, 163(12), 1-17. http://doi.org/10.1001/archpediatrics.2009.214

Davis, A. S., Moss, L. E., Nogin, M. M., \& Webb, N. E. (2015). Neuropsychology of child 
maltreatment and implications for school psychologists. Psychology in the Schools, 52(1), 77-91. http://doi.org/10.1002/pits.21806

Davis, J. S., Fani, N., Ressler, K., Jovanovic, T., Tone, E. B., \& Bradley, B. (2014). Attachment anxiety moderates the relationship between childhood maltreatment and attention bias for emotion in adults. Psychiatry Research, 217(1-2), 79-85. http://doi.org/10.1016/j.psychres.2014.03.010

DeCasper, A. J., \& Carstens, A. A. (1981). Contingencies of stimulation: Effects on learning and emotion in neonates. Infant Behavior \& Development, 4(1), 19-35. http://dx.doi.org/10.1016/S0163-6383(81)80004-5

De Bellis, M. D., Keshavan, M. S., Spencer, S., \& Hall, J. (2000). N-Acetylaspartate concentration in the anterior cingulate of maltreated children and adolescents with PTSD. American Journal of Psychiatry, 157(7), 1175-1177.

Dennison, M. J., Sheridan, M. A., Busso, D. S., Jenness, J. L., Peverill, M., Rosen, M. L., \& Mclaughlin, K. A. (2016). Neurobehavioral markers of resilience to depression amongst adolescents exposed to child abuse. Journal of Abnormal Psychology, 125(8), 1201-1212. doi:http://dx.doi.org/10.1037/abn0000215

DeSteno, D. A., \& Schmauss, C. (2009). A role for dopamine D2 receptors in reversal learning. Neuroscience, 162(1), 118-127. http://doi.org/10.1016/j.neuroscience.2009.04.052

Dillon D. G., Holmes A. J., Birk J. L., Brooks N., Lyons-Ruth K., Pizzagalli D. A. (2009). Childhood adversity is associated with left basal ganglia dysfunction during reward anticipation in adulthood. Biological Psychiatry 66, 206-213.

Fang, X., Brown, D. S., Florence, C. S., \& Mercy, J. A. (2012). The economic burden of child maltreatment in the United States and implications for prevention. Child Abuse \& 
Neglect, 36(2), 156-165. http://doi.org/10.1016/j.chiabu.2011.10.006

Fang, X., \& Corso, P. S. (2007). Child maltreatment, youth violence, and intimate partner violence. American Journal of Preventive Medicine, 33(4), 281-290. http://doi.org/10.1016/j.amepre.2007.06.003

Felitti, M. D., Vincent, J., Anda, M. D., \& Robert, F. (1998). Relationship of childhood abuse and household dysfunction to many of the leading causes of death in adults: The adverse childhood experiences (ACE) study. American Journal of Preventative Medicine, 14(4), 245-258. http://doi.org/10.1016/S0749-3797(98)00017-8

Field, M., Duka, T., Tyler, E., \& Schoenmakers, T. (2009). Attentional bias modification in tobacco smokers. Nicotine \& Tobacco Research, 11(7), 812-822. http://doi.org/10.1093/ntr/ntp067

Frank, M. J., \& Claus, E. D. (2006). Anatomy of a decision: Striato-orbitofrontal interactions in reinforcement learning, decision making, and reversal. Psychological Review, 113(2), 300-326. http://doi.org/10.1037/0033-295X.113.2.300

Fraser, M. W., Galinsky, M. J., Smokowski, P. R., Day, S. H., Terzian, M. A., Rose, R. A., \& Guo, S. (2005). Social information-processing skills training to promote social competence and prevent aggressive behavior in the third grades. Journal of Consulting and Clinical Psychology, 73(6), 1045-1055. http://doi.org/10.1037/0022-006X.73.6.1045

Galvan, A., Hare, T. A., Parra, C. E., Penn, J., Voss, H., Glover, G., \& Casey, B. J. (2006). Earlier development of the accumbens relative to orbitofrontal cortex might underlie risktaking behavior in adolescents. The Journal of Neuroscience, 26(25), 6885-6892. http://doi.org/10.1523/JNEUROSCI.1062-06.2006

Gibb, B. E. (2002). Childhood maltreatment and negative cognitive styles. Clinical Psychology 
Review, 22(2), 223-246. http://doi.org/10.1016/S0272-7358(01)00088-5

Gibb, B. E., McGeary, J. E., \& Beevers, C. G. (2015). Attentional biases to emotional stimuli: key components of the RDoC constructs of sustained threat and loss. American Journal of Medical Genetics Part B: Neuropsychiatric Genetics, 171(1), 65-80. http://doi.org/10.1002/ajmg.b.32383

Gilbert, R., Widom, C. S., Browne, K., Fergusson, D., Webb, E., \& Johnson, S. (2009). Burden and consequences of child maltreatment in high-income countries. The Lancet, 373(9657), 68-81. http://doi.org/10.1016/S0140-6736(08)61706-7

Gorka, A. X., Hanson, J. L., Radtke, S. R., \& Hariri, A. R. (2014). Reduced hippocampal and medial prefrontal gray matter mediate the association between reported childhood maltreatment and trait anxiety in adulthood and predict sensitivity to future life stress. Biology of Mood and Anxiety Disorders, 4, doi: 10.1186/2045-5380-4-12

Gos, T., Bock, J., Poeggel, G., \& Braun, K. (2008). Stress-induced synaptic changes in the rat anterior cingulate cortex are dependent on endocrine developmental time windows. Synapse, 62(3), 229-232. http://doi.org/10.1002/syn.20477

Gottfried, J. A., O'Doherty, J., \& Dolan, R. J. (2003). Encoding predictive reward value in human amygdala and orbitofrontal cortex. Science, 301(5636), 1104-1107. http://doi.org/10.1126/science.1087919

Gunnar MR, Donzella B. Social regulation of the cortisol levels in early human development. Psychoneuroendocrinology. 2002;27:199-220. doi: 10.1016/S03064530(01)00045-2.

Guyer, A. E., Kaufman, J., Hodgdon, H. B., Masten, C. L., Jazbec, S., Pine, D. S., \& Ernst, M. (2006). Behavioral alterations in reward system function. Journal of the American 
Academy of Child and Adolescent Psychiatry, 45(9), 1059-1067.

http://doi.org/10.1097/01.chi.0000227882.50404.11

Haber, S. N. (2003). The primate basal ganglia: Parallel and integrative networks. Journal of Chemical Neuroanatomy, 26(4), 317-330. http://doi.org/10.1016/j.jchemneu.2003.10.003

Haber, S. N., \& Knutson, B. (2010). The reward circuit: Linking primate anatomy and human imaging. Neuropsychopharmacology, 35(1), 4-26. doi: 10.1038/npp.2009.129.

Hanish, L. D., Eisenberg, N., Fabes, R. A., Spinrad, T. L., Ryan, P., \& Schmidt, S. (2004). The expression and regulation of negative emotions: Risk factors for young children's peer victimization. Development and Psychopathology, 16, 335-353.

Hanson, J. L., Adluru, N., Chung, M. K., Alexander, A. L., Davidson, R. J., \& Pollak, S. D. (2013a). Early neglect is associated with alterations in white matter integrity and cognitive functioning. Child Development, 84(5), 1566-1578. http://doi.org/10.1111/cdev.12069

Hanson, J. L., Albert, W. D., Iselin, A. M. R., Carré, J. M., Dodge, K. A., \& Hariri, A. R. (2016). Cumulative stress in childhood is associated with blunted reward-related brain activity in adulthood. Social Cognitive and Affective Neuroscience, 11(3): 405-412.

Hanson, J. L., Bos, W., Roeber, B. J., Rudolph, K. D., Davidson, R. J., \& Pollak, S. D. (2017). Early adversity and learning: implications for typical and atypical behavioral development. Journal of Child Psychology and Psychiatry, 58(7), 770-778. doi: $10.1111 /$ jcpp.12694

Hanson, J. L., Chung, M. K., Avants, B. B., Rudolph, K. D., Shirtcliff, E. A., Gee, J. C., ... Pollak, S. D. (2012). Structural variations in prefrontal cortex mediate the relationship between early childhood stress and spatial working memory. The Journal of 
Neuroscience, 32(23), 7917-7925. doi: 10.1523/JNEUROSCI.0307-12.2012

Hanson, J. L., Chung, M. K., Avants, B. B., Shirtcliff, E. A., Gee, J. C., Davidson, R. J., \& Pollak, S. D. (2010). Early stress is associated with alterations in the orbitofrontal cortex: A tensor-based morphometry investigation of brain structure and behavioral risk. The Journal of Neuroscience, 30(22), 7466-7472. http://doi.org/10.1523/JNEUROSCI.085910.2010

Hanson, J. L., Hair, N., Shen, D. G., Shi, F., Gilmore, J. H., Wolfe, B. L., \& Pollak, S. D. (2013b). Family poverty affects the rate of human infant brain growth. PloS One, 8(12), e80954-9. http://doi.org/10.1371/journal.pone.0080954

Hanson, J.L., Hariri, A.R., \& Williamson, D.E. (2015). Blunted ventral striatum development in adolescence reflects emotional neglect and predicts depressive symptoms. Biological Psychiatry, doi:10.1016/j.biopsych.2015.05.010.

Hanson, J. L., Knodt, A. R., Brigidi, B. D., \& Hariri, A. R. (2015). Lower structural integrity of the uncinate fasciculus is associated with a history of child maltreatment and future psychological vulnerability to stress. Development and Psychopathology, 27, 16111619.

Hanson, J. L., Nacewicz, B. M., Sutterer, M. J., Cayo, A. A., Schaefer, S. M., Rudolph, K. D., ... Davidson, R. J. (2015). Behavioral problems after early life stress: Contributions of the hippocampus and amygdala. Biological Psychiatry, 77(4), 314-323. http://doi.org/10.1016/j.biopsych.2014.04.020

Harms, M.B., Shannon-Bowen, K., Hanson, J. D., \& Pollak, S. D. (2017). Instrumental Learning and Cognitive Flexibility are Impaired in Children Exposed to Early Life Stress. Developmental Science. DOI: 10.1111/desc.12596 
Hart, H., \& Rubia, K. (2012). Neuroimaging of child abuse: a critical review. Frontiers in Human Neuroscience, 6(52), doi: 10.3389/fnhum.2012.00052. eCollection 2012.

Heleniak, C., Jenness, J. L., Vander Stoep, A., McCauley, E., \& McLaughlin, K. A. (2015). Childhood maltreatment exposure and disruptions in emotion regulation: A transdiagnostic pathway to adolescent internalizing and externalizing psychopathology. Cognitive Therapy and Research, 1-22. http://doi.org/10.1007/s10608-015-9735-z

Helmeke, C., Seidel, K., Poeggel, G., Bredy, T. W., Abraham, A., \& Braun, K. (2009). Paternal deprivation during infancy results in dendrite- and time-specific changes of dendritic development and spine formation in the orbitofrontal cortex of the biparental rodent Octodon Degus. Neuroscience, 163(3), 790-798. http://doi.org/10.1016/j.neuroscience.2009.07.008

Herringa, R. J., Birn, R. M., \& Ruttle, P. L. (2013). Childhood maltreatment is associated with altered fear circuitry and increased internalizing symptoms by late adolescence. Proceedings of the National Academy of Science, 110(47), 19119-19124. http://doi.org/10.1073/pnas.1310766110/-/DCSupplemental

Hilt, L. M., \& Pollak, S. D. (2012). Getting out of rumination: Comparison of three brief interventions in a sample of youth. Journal of Abnormal Child Psychology, 40(7), 11571165. http://doi.org/10.1007/s10802-012-9638-3

Hilt, L. M., \& Pollak, S. D. (2013). Characterizing the ruminative process in young adolescents. Journal of Clinical Child and Adolescent Psychology, 42(4), 519-530. http://doi.org/10.1080/15374416.2013.764825

Hilt, L. M., Leitzke, B. T., \& Pollak, S. D. (2014). Cognitive control and rumination in youth: The importance of emotion. Journal of Experimental Psychopathology, 5(3), 302-313. 
http://doi.org/10.5127/jep.038113

Holz, N. E., Boecker, R., Hohm, E., Zohsel, K., Buchmann, A. F., Blomeyer, D., ... Laucht, M. (2015). The long-term impact of early life poverty on orbitofrontal cortex volume in adulthood: Results from a prospective study over 25 years. Neuropsychopharmacology, 40(4), 996-1004. http://doi.org/10.1038/npp.2014.277

Honey, C. J., Kötter, R., \& Breakspear, M. (2007). Network structure of cerebral cortex shapes functional connectivity on multiple time scales. Proceedings of the National Academy of Sciences, 104(24), 10240-10245. http://doi.org/10.1073/pnas.0701519104

Hostinar, C. E., \& Gunnar, M. R. (2013). The developmental effects of early life stress: An overview of current theoretical frameworks. Current Directions in Psychological Science, 22(5), 400-406. http://doi.org/10.1177/0963721413488889

Hostinar, C. E., Cicchetti, D., \& Rogosch, F. A. (2014). Oxytocin receptor gene polymorphism, perceived social support, and psychological symptoms in maltreated adolescents.

Development and Psychopathology, 26(02), 465-477.

http://doi.org/10.1017/S0954579414000066

Jaffee, S. R., Caspi, A., Moffitt, T. E., \& Taylor, A. (2004). Physical maltreatment victim to antisocial child: Evidence of an environmentally mediated process. Journal of Abnormal Psychology, 113(1), 44-55. http://doi.org/10.1037/0021-843X.113.1.44

Kaplow, J. B., \& Widom, C. S. (2007). Age of onset of child maltreatment predicts long-term mental health outcomes. Journal of Abnormal Psychology, 116(1), 176-187. http://dx.doi.org/10.1037/0021-843X.116.1.176

Keil, V., \& Price, J. M. (2009). Social information-processing patterns of maltreated children in two social domains. Journal of Applied Developmental Psychology, 30(1), 43-52. 
http://doi.org/10.1016/j.appdev.2008.10.003

Kiecolt-Glaser, J. K., Gouin, J. P.,Weng, N. P., Malarkey,W. B., Beversdorf, D. Q., \& Glaser, R. (2011). Childhood adversity heightens the impact of later-life caregiving stress on telomere length and inflammation. Psychosomatic Medicine, 73, 16-22. http://doi.org/10.1097/PSY.0b013e31820573b6

Kim-Spoon, I., Cicchetti, D., \& Rogosch, F.A. (2013). A longitudinal study of emotion regulation, emotion lability-negativity, and internalizing symptomatology in maltreated and nonmaltreated children. Child Development, 84(2), 512-27. doi: 10.1111/j.1467-8624.2012.01857.x

Koenen, K. C., Moffitt, T. E., Poulton, R., Martin, J., \& Caspi, A. (2007). Early childhood factors associated with the development of post-traumatic stress disorder: Results from a longitudinal birth cohort. Psychological Medicine, 37(02), 181-192. http://doi.org/10.1017/S0033291706009019

Koizumi, M., \& Takagish, H. (2014). The relationship between child maltreatment and emotion recognition. PLOS One, https://doi.org/10.1371/journal.pone.0086093

Koss, K. J., Hostinar, C. E., Donzella, B., \& Gunnar, M. R. (2014). Social deprivation and the HPA axis in early development. Psychoneuroendocrinology, 50, 1-13. http://doi.org/10.1016/j.psyneuen.2014.07.028

Krain Roy, A., Vasa, R. A. Bruck, M., Mogg, K., Bradley, B. P., Sweeney, M. et al. (2008). Attention bias to threat in pediatric anxiety disorders. Journal of the American Academy of Child and Adolescent Psychiatry, 47, 1189-1196. doi: 10.1097/CHI.0b013e3181825ace

Kringelbach, M. \& Rolls, E. (2004). The functional neuroanatomy of the human orbitofrontal 
cortex: Evidence from neuroimaging and neuropsychology. Progress in Neurobiology, 72(5), 341-372. http://doi.org/10.1016/j.pneurobio.2004.03.006

Lauterbach, D., \& Armour, C. (2015). Symptom trajectories among child survivors of maltreatment: Findings from the longitudinal studies of child abuse and neglect (LONGSCAN). Journal of Abnormal Child Psychology, 1-11. http://doi.org/10.1007/s10802-015-9998-6

Leeb, R.T., Paulozzi, L., Melanson, C., Simon, T., \& Arias, I. (2008). Child maltreatment surveillance: Uniform definitions for public health and recommended data elements. Centers for Disease Control and Prevention, National Center for Injury Prevention and Control.

Lemerise, E. A., \& Arsenio, W. F. (2000). An integrated model of emotion processes and cognition in social information processing. Child Development, 71(1), 107-118. http://doi.org/10.1111/1467-8624.00124

Lim, L., Hart, H., Mehta, M. A., Simmons, A., Mirza, K., \& Rubia, K. (2015). Neural correlates of error processing in young people with a history of severe childhood abuse: An fMRI study. American Journal of Psychiatry, 172(9), 892-900. http://doi.org/10.1176/appi.ajp.2015.14081042

Linetzky, M., Pergamin-Hight, L., Pine, D. S., \& Bar-Haim, Y. (2015). Quantitative evaluation of the clinical efficacy of attention bias modification treatment for anxiety disorders. Depression and Anxiety, 32(6), 383-391. http://doi.org/10.1002/da.22344

Liston, C., Miller, M. M., Goldwater, D. S., Radley, J. J., Rocher, A. B., Hof, P. R., ... McEwen, B. S. (2006). Stress-induced alterations in prefrontal cortical dendritic morphology predict selective impairments in perceptual attentional set-shifting. The Journal of 
Neuroscience, 26(30), 7870-7874. http://doi.org/10.1523/JNEUROSCI.1184-06.2006

Loman, M. M., Johnson, A. E., Westerlund, A., Pollak, S. D., Nelson, C. A., \& Gunnar, M. R. (2012). The effect of early deprivation on executive attention in middle childhood. Journal of Child Psychology and Psychiatry, 54(1), 37-45. http://doi.org/10.1111/j.14697610.2012.02602.x

Lupien, S. J., McEwen, B. S., Gunnar, M. R., \& Heim, C. (2009). Effects of stress throughout the lifespan on the brain, behaviour and cognition. Nature Reviews Neuroscience, 10(6), 434-445. http://doi.org/10.1038/nrn2639

Lyons-Ruth, K., \& Block, D. (1996). The disturbed caregiving system: Relations among childhood trauma, maternal caregiving, and infant affect and attachment. Infant Mental Health Journal, 17(3), 257-275. http://doi.org/10.1002/(SICI)10970355(199623)17:3<257::AID-IMHJ5>3.0.CO;2-L

Macleod, C., Rutherford, E., Campbell, L., Ebsworthy, G., \& Holker, L. (2002). Selective attention and emotional vulnerability: Assessing the causal basis of their association through the experimental manipulation of attentional bias. Journal of Abnormal Psychology, 111(1), 107-123. http://doi.org/10.1037//0021-843X.111.1.107

Mason, W. A., \& Capitanio, J. P. (1988). Formation and expression of filial attachment in Rhesus monkeys raised with living and inanimate mother substitutes. Developmental Psychobiology. http://doi.org/10.1002/dev.420210502/pdf

Mason, W. A., \& Kenney, M. D. (1974). Redirection of filial attachments in Rhesus monkeys: dogs as mother surrogates. Science, 183(4130), 1209-1211. http://doi.org/10.1126/science.183.4130.1209

Masten CL, Guyer AE, Hodgdon HB, McClure EB, Charney DS, Ernst M, et al. Recognition of 
facial emotions among maltreated children with high rates of post-traumatic stress disorder. Child Abuse \& Neglect. 2008;32:139-153. doi:

10.1016/j.chiabu.2007.09.006.

Matthews, K., \& Robbins, T. W. (2003). Early experience as a determinant of adult behavioural responses to reward: The effects of repeated maternal separation in the rat. Neuroscience \& Biobehavioral Reviews, 27, 45-55. http://doi.org/10.1016/S0149-7634(03)00008-3

McCrory, E., De Brito, S. A., \& Viding, E. (2010). Research Review: The neurobiology and genetics of maltreatment and adversity. Journal of Child Psychology and Psychiatry, 51(10), 1079-1095. http://doi.org/10.1111/j.1469-7610.2010.02271.x

McCrory, E., De Brito, S. A., \& Viding, E. (2012). The link between child abuse and psychopathology: A review of neurobiological and genetic research. Journal of the Royal Society of Medicine, 105(4), 151-156. http://doi.org/10.1258/jrsm.2011.110222

McLaughlin, K. A., Peverill, M., Gold, A. L., Alves, S., \& Sheridan, M. A. (2015). Child maltreatment and neural systems underlying emotion regulation. Journal of the American Academy of Child \& Adolescent Psychiatry, 54(9), 753-762. http://doi.org/10.1016/j.jaac.2015.06.010

Mehta, M. A., Gore-Langton, E., Golembo, N., Colvert, E., Williams, S. C., \& Sonuga-Barke, E. (2010). Hyporesponsive reward anticipation in the basal ganglia following severe institutional deprivation early in life. Journal of Cognitive Neuroscience, 22(10), 23162325. http://doi.org/10.1162/jocn.2009.21394

Miller, G. E., Chen, E., \& Parker, K. J. (2011). Psychological stress in childhood and susceptibility to the chronic diseases of aging: Moving toward a model of behavioral and biological mechanisms. Psychological Bulletin, 137(6), 959-997. 
http://doi.org/10.1037/a0024768

Mogg, K., Waters, A. M., \& Bradley, B. P. (2017). Attention Bias Modification (ABM): Review of Effects of Multisession ABM Training on Anxiety and Threat-Related Attention in High-Anxious Individuals. Clinical Psychological Science, 5(4), 698-717. http://doi.org/10.1177/2167702617696359

Mogoaşe, C., David, D., \& Koster, E. H. W. (2014). Clinical efficacy of attentional bias modification procedures: An updated meta-analysis. Journal of Clinical Psychology, 70(12), 1133-1157. http://doi.org/10.1002/jclp.22081

Moles, A., Kieffer, B. L., \& D'Amato, F. R. (2004). Deficit in attachment behavior in mice lacking the $\mu$-opioid receptor gene. Science, 304(5679), 1983-1986. http://doi.org/10.1126/science.1095943

Morris, A. S., Silk, J. S., Steinberg, L., Myers, S. S., \& Robinson, L. R. (2007). The role of the family context in the development of emotion regulation. Social Development, 16, 361388. doi: $\underline{10.1111 / j .1467-9507.2007 .00389 . x}$

Mueller, S. C., Hardin, M. G., Korelitz, K., Daniele, T., Bemis, J., Dozier, M., ... Ernst, M. (2012). Incentive effect on inhibitory control in adolescents with early-life stress: An antisaccade study. Child Abuse \& Neglect, 36(3), 217-225. http://doi.org/10.1016/j.chiabu.2011.10.010

Mueller, S. C., Maheu, F. S., Dozier, M., Peloso, E., Mandell, D., Leibenluft, E., ... Ernst, M. (2010). Early-life stress is associated with impairment in cognitive control in adolescence: An fMRI study. Neuropsychologia, 48(10), 3037-3044. http://doi.org/10.1016/j.neuropsychologia.2010.06.013

Murray, E. A., O'Doherty, J. P., \& Schoenbaum, G. (2007). What we know and do not know 
about the functions of the orbitofrontal cortex after 20 years of cross-species studies. The Journal of Neuroscience, 27(31), 8166-8169. http://doi.org/10.1523/JNEUROSCI.155607.2007

Nanni, V., Uher, R., \& Danese, A. (2014). Childhood maltreatment predicts unfavorable course of illness and treatment outcome in depression: A meta-analysis. American Journal of Psychiatry. http://doi.org/10.1176/appi.ajp.2011.11020335

Neece, L. C., Green, S. A., \& Baker, B. L. (2012). Parenting stress and child behavior problems: A transactional relationship across time. American Journal of Intellectual Developmental Disabilities, 117, 48-66. http://doi.org/10.1352/1944-7558-117.1.48

Nolen-Hoeksema, S., Wisco, B. E., \& Lyubomirsky, S. (2008). Rethinking rumination. Perspectives on Psychological Science, 3(5), 400-424. http://doi.org/10.1111/j.17456924.2008.00088.x

Norman, R. E., Byambaa, M., De, R., Butchart, A., Scott, J., \& Vos, T. (2012). The long-term health consequences of child physical abuse, emotional abuse, and neglect: a systematic review and meta-analysis. PLoS Med, 9, e1001349.

Oldershaw, L., Walters, G. C., \& Hall, D. K. (1986). Control strategies and noncompliance in abusive mother-child dyads: An observational study. Child Development. 722-732. http://doi.org/10.2307/1130349

Palma-Gudiel, H., Córdova-Palomera, A., Leza, J. C., \& Fañanás, L. (2015). Glucocorticoid receptor gene (NR3C1) methylation processes as mediators of early adversity in stressrelated disorders causality: A critical review. Neuroscience \& Biobehavioral Reviews, 55, 520-535. http://doi.org/10.1016/j.neubiorev.2015.05.016

Papoušek, H., \& Papoušek, M. (2008). Cognitive aspects of preverbal social interaction between 
human infants and adults. In Ciba Foundation Symposium 33 - Parent-Infant Interaction (pp. 241-269). Chichester, UK: John Wiley \& Sons, Ltd.

http://doi.org/10.1002/9780470720158.ch14

Passingham, R. E., Stephan, K. E., \& Kötter, R. (2002). The anatomical basis of functional localization in the cortex. Nature Reviews Neuroscience, 3(8), 606-616. http://doi.org/10.1038/nrn893

Paul, E., \& Eckenrode, J. (2015). Childhood psychological maltreatment subtypes and adolescent depressive symptoms. Child Abuse \& Neglect, 47, 38-47. http://doi.org/10.1016/j.chiabu.2015.05.018

Pechtel, P., \& Pizzagalli, D.A. Effects of early life stress on cognitive and affective function: an integrated review of human literature. (2011). Psychopharmacology, 214(1), 5570.

Pechtel, P., \& Pizzagalli, D. A. (2013). Disrupted reinforcement learning and maladaptive behavior in women with a history of childhood sexual abuse. JAMA Psychiatry, 70, 499-507.

Penton-Voak, I. S., Bate, H., Lewis, G., \& Munafo, M. R. (2012). Effects of emotion perception training on mood in undergraduate students: randomised controlled trial. The British Journal of Psychiatry, 201(1), 71-72. http://doi.org/10.1192/bjp.bp.111.107086

Penton-Voak, I. S., Thomas, J., Gage, S. H., McMurran, M., McDonald, S., \& Munafo, M. R. (2013). Increasing recognition of happiness in ambiguous facial expressions reduces anger and aggressive behavior. Psychological Science, 24(5), 688-697. http://doi.org/10.1177/0956797612459657 
Pergamin-Hight, L., Naim, R., Bakermans-Kranenburg, M. J., Van Ijzendoorn, M. H., \& BarHaim, Y. (2015). Content specificity of attention bias to threat in anxiety disorders: A meta-analysis. Clinical Psychology Review, 35(C), 10-18. http://doi.org/10.1016/j.cpr.2014.10.005

Perlman, S. B., Kalish, C. W., \& Pollak, S. D. (2008). The role of maltreatment experience in children's understanding of the antecedents of emotion. Cognition and Emotion, 22(4), 651-670. http://doi.org/10.1080/02699930701461154

Pollak, S. D. (2015). Multilevel developmental approaches to understanding the effects of child maltreatment: Recent advances and future challenges. Development and Psychopathology, 27(4, Pt. 2), 1387-1397.

Pollak, S. D., Cicchetti, D., Hornung, K., \& Reed, A. (2000). Recognizing emotion in faces: Developmental effects of child abuse and neglect. Developmental Psychology, 36(5), 679-688. http://doi.org/10.1037//0012-1649.36.5.679

Pollak, S. D., \& Kistler, D. J. (2002). Early experience is associated with the development of categorical representations for facial expressions of emotion. Proceedings of the National Academy of Sciences of the United States of America, 99(13), 9072-9076.

Pollak, S. D., Nelson, C. A., Schlaak, M. F., Roeber, B. J., Wewerka, S. S., Wiik, K. L., ... Gunnar, M. R. (2010). Neurodevelopmental effects of early deprivation in postinstitutionalized children. Child Development, 81(1), 224-236. http://doi.org/10.1111/j.1467-8624.2009.01391.x

Pollak, S. D., \& Sinha, P. Effects of early experience on children's recognition of facial displays of emotion. Developmental Psychology, 38, 784-791.

Pollak, S. D., Vardi, S., Putzer Bechner, A. M., \& Curtin, J. J. (2005). Physically abused 
children's regulation of attention in response to hostility. Child Development, 76(5), 968977. http://doi.org/10.1111/j.1467-8624.2005.00890.x

Poulton, R., Moffitt, T. E., \& Silva, P. A. (2015). The Dunedin multidisciplinary health and development study: Overview of the first 40 years, with an eye to the future. Social psychiatry and psychiatric epidemiology, 50(5), 679-693 http://doi.org/10.1007/s00127$015-1048-8$

Pryce, C. R., Dettling, A. C., Spengler, M., Schnell, C. R., \& Feldon, J. (2004). Deprivation of parenting disrupts development of homeostatic and reward systems in Marmoset monkey offspring. Biological Psychiatry, 56(2), 72-79. http://doi.org/10.1016/j.biopsych.2004.05.002

Quiggle, N. L., Garber, J., \& Panak, W. F. (1992). Social information processing in aggressive and depressed children. Child Development, 63(6), 1305-1320. http://doi.org/10.1111/j.1467-8624.1992.tb01696.x/full

Ramrakha, S., Bell, M. L., Paul, C., \& Dickson, N. (2007). Childhood behavior problems linked to sexual risk taking in young adulthood: A birth cohort study. Journal of the American Academy of Child and Adolescent Psychiatry, 46(10), 1272-1279. http://doi.org/10.1097/chi.0b013e3180f6340e

Renwick, B., Campbell, I. C., \& Schmidt, U. (2013). Attention bias modification: A new approach to the treatment of eating disorders? International Journal of Eating Disorders, 46(5), 496-500. http://doi.org/10.1002/eat.22107

Reynolds, A. J. \& Robertson, D. L. (2003). School-based early intervention and later child maltreatment in the Chicago longitudinal study. Child Development, 74(1), 3-26. http://doi.org/10.1111/1467-8624.00518 
Ridderinkhof, K. R. (2004). The role of the medial frontal cortex in cognitive control. Science, 306(5695), 443-447. http://doi.org/10.1126/science.1100301

Ringeisen, H., Casanueva, C. E., Urato, M., \& Stambaugh, L. F. (2009). Mental health service use during the transition to adulthood for adolescents reported to the child welfare system. Psychiatric Services, 60, 1084-1091.

Rohrbeck, C. A., \& Twentyman, C. T. (1986). Multimodal assessment of impulsiveness in abusing, neglecting, and nonmaltreating mothers and their preschool children. Journal of Consulting and Clinical Psychology, 54(2), 231. http://doi.org/10.1037/0022006X.54.2.231

Romens, S. E., \& Pollak, S. D. (2011). Emotion regulation predicts attention bias in maltreated children At-risk for depression. Journal of Child Psychology and Psychiatry, 53(2), 120127. http://doi.org/10.1111/j.1469-7610.2011.02474.x

Romens, S. E., McDonald, J., Svaren, J., \& Pollak, S. D. (2014). Associations between early life stress and gene methylation in children. Child Development, 86(1), 303-309. http://doi.org/10.1111/cdev.12270

Schoenbaum, G., Roesch, M. R., Stalnaker, T. A., \& Takahashi, Y. K. (2009). A new perspective on the role of the orbitofrontal cortex in adaptive behaviour. Nature Reviews Neuroscience, 10(12), 885-892. http://doi.org/10.1038/nrn2753

Schultz, W., \& Dickinson, A. (2000). Neuronal coding of prediction errors. Annual Review of Neuroscience, 23(1), 473-500. http://doi.org/10.1146/annurev.neuro.23.1.473

Schultz, W., Dayan, P., \& Montague, P. R. (1997). A neural substrate of prediction and reward. Science, 275(5306), 1593-1599. http://doi.org/10.1126/science.275.5306.1593

Seltzer, L. J., Ziegler, T., Connolly, M. J., Prososki, A. R., \& Pollak, S. D. (2013). Stress- 
induced elevation of oxytocin in maltreated children: Evolution, neurodevelopment, and social behavior. Child Development, 85(2), 501-512. http://doi.org/10.1111/cdev.12136

Shackman, J. E., \& Pollak, S. D. (2014). Impact of physical maltreatment on the regulation of negative affect and aggression. Development and Psychopathology, 1-13. http://doi.org/10.1017/S0954579414000546

Shackman, J. E., Fatani, S., Camras, L. A., Berkowitz, M. J., Bachorowski, J.-A., \& Pollak, S. D. (2010). Emotion expression among abusive mothers is associated with their children's emotion processing and problem behaviours. Cognition and Emotion, 24(8), 1421-1430. http://doi.org/10.1080/02699930903399376

Shackman, J. E., Shackman, A. J., \& Pollak, S. D. (2007). Physical abuse amplifies attention to threat and increases anxiety in children. Emotion, 7(4), 838-852. http://doi.org/10.1037/1528-3542.7.4.838

Shechner, T., \& Bar-Haim, Y. (2016). Threat monitoring and attention-bias modification in anxiety and stress-related disorders. Current Directions in Psychological Science, 25(6), 431-437. http://doi.org/10.1177/0963721416664341

Shechner, T., Britton, J. C., Pérez-Edgar, K., Bar-Haim, Y., Ernst, M., Fox, N. A., ... \& Pine, D. S. (2011). Attention biases, anxiety, and development: Toward or away from threats or rewards? Depression and Anxiety, 29(4), 282-294. http://doi.org/10.1002/da.20914

Sheridan, M. A., Fox, N. A., \& Zeanah, C. H. (2012). Variation in neural development as a result of exposure to institutionalization early in childhood. Proceedings of the National Academy of Sciences, 109(32), 12927-12932. http://doi.org/10.1073/pnas.1200041109//DCSupplemental

Shipman, K. L., Schneider, R., Fitzgerald, M. M., Sims, C., Swisher, L., \& Edwards, A. (2007). 
Maternal emotion socialization in maltreating and non-maltreating families: Implications for children's emotion regulation. Social Development, 16(2), 268-285. http://doi.org/10.1111/j.1467-9507.2007.00384.x

Shirtcliff, E. A., Coe, C. L., \& Pollak, S. D. (2009). Early childhood stress is associated with elevated antibody levels to herpes simplex virus type 1 . Proceedings of the National Academy of Sciences, 106(8), 2963-2967. http://doi.org/10.1073/pnas.0806660106

Shonkoff, J. P., Garner, A. S., \& \& the Committee on Psychosocial, Developmental, and Behavioral Pediatrics (2012). The lifelong effects of early childhood adversity and toxic stress. Pediatrics, 129(1), e232-e246. http://doi.org/10.1542/peds.2011-2663

Singer, M. J., Humphreys, K. L., \& Lee, S. S. (2016). Coping self-efficacy mediates the association between child abuse and ADHD in adulthood. Journal of Attention Disorders, 20(8):695-703. doi: 10.1177/1087054712465337.

Slavich, G. M., \& Cole, S. W. (2013). The emerging field of human social genomics. Clinical Psychological Science, 1(3), 331-348. http://doi.org/10.1177/2167702613478594

Springer KW, Sheridan J, Kuo D, Carnes M. Long-term physical and mental health consequences of childhood physical abuse: Results from a large population-based sample of men and women. Child Abuse \& Neglect. 2007;31:517-530.

Stoddard, J., Sharif-Askary, B., Harkins, E. A., Frank, H. R., Brotman, M. A., Penton-Voak, I. S., et al. (2016). An open pilot study of training hostile interpretation bias to treat disruptive mood dysregulation disorder. Journal of Child and Adolescent Psychopharmacology, 26(1), 49-57. http://doi.org/10.1089/cap.2015.0100

Taylor, S. E., Way, B. M., \& Seeman, T. E. (2011). Early adversity and adult health outcomes. Development And Psychopathology, 23(3), 939-954. 
http://doi.org/10.1017/S0954579411000411

Teicher, M. H., Anderson, C. M., Ohashi, K., \& Polcari, A. (2014). Childhood maltreatment: altered network centrality of cingulate, precuneus, temporal pole and insula. Biological Psychiatry, 76(4), 297-305. http://doi.org/10.1016/j.biopsych.2013.09.016

Teisl, M., \& Cicchetti, D. (2007). Physical abuse, cognitive and emotional processes, and aggressive/disruptive behavior problems. Social Development, 17(1), 1-23. http://doi.org/10.1111/j.1467-9507.2007.00412.x

Thomaes, K., Dorrepaal, E., \& Draijer, N. (2010). Reduced anterior cingulate and orbitofrontal volumes in child abuse-related complex PTSD. Journal of Clinical Psychiatry, 71(12), 1636. http://doi.org/10.4088/JCP.08m04754blu

Thompson, R. A. (1994). Emotion regulation: A theme in search of a definition. The development of emotion regulation: Biological and behavioral considerations. In: Fox NA, editor. Monographs of the Society for Research in Child Development, 59, 25 52. pp. 2-3. Serial No. 240

Thornberry, T. P., Henry, K. L., Ireland, T. O., \& Smith, C. A. (2010). The causal impact of childhood-limited maltreatment and adolescent maltreatment on early adult adjustment. Journal of Adolescent Health, 46(4), 359-365. http://doi.org/10.1016/j.jadohealth.2009.09.011

Timmons, A. C., \& Margolin, G. (2014). Family conflict, mood, and adolescents' daily achool problems: Moderating roles of internalizing and externalizing symptoms. Child Development, 86(1), 241-258. http://doi.org/10.1111/cdev.12300

Vachon, D. D., Krueger, R. F., Rogosch, F. A., \& Cicchetti, D. (2015). Assessment of the harmful psychiatric and behavioral effects of different forms of child maltreatment. 
JAMA Psychiatry, 72(11), 1135-8. http://doi.org/10.1001/jamapsychiatry.2015.1792

Wasserman, E. A., \& Miller, R. R. (1997). What's elementary about associative learning? Annual Review of Psychology, 48(1), 573-607. http://doi.org/10.1146/annurev.psych.48.1.573

Weaver, I. C. (2005). Reversal of maternal programming of stress responses in adult offspring through methyl supplementation: Altering epigenetic marking later in life. The Journal of Neuroscience, 25(47), 11045-11054. http://doi.org/10.1523/JNEUROSCI.3652-05.2005

Weaver, I. C., Hellstrom, I. C., Brown, S. E., Andrews, S. D., Dymov, S., Diorio, J., ... Meaney, M. J. (2014). The methylated-DNA binding protein MBD2 enhances NGFI-A (egr-1)mediated transcriptional activation of the glucocorticoid receptor. Philosophical Transactions of the Royal Society B: Biological Sciences, 369(1652), 20130513. http://doi.org/10.1098/rstb.2013.0513

Weder, N., Zhang, H., Jensen, K., Yang, B. Z., Simen, A., Jackowski, A., ... O'Loughlin, K. (2014). Child Abuse, Depression, and Methylation in Genes involved with Stress, Neural Plasticity, and Brain Circuitry. Journal of the American Academy of Child \& Adolescent Psychiatry, 53(4), 417-424. http://doi.org/10.1016/j.jaac.2013.12.025

Weller, J. A., \& Fisher, P. A. (2013). Decision-making Deficits among Maltreated Children. Child Maltreatment, 18(3), 184-194. http://doi.org/10.1177/1077559512467846

Whipple, E. E. \& Webster-Stratton, C. (1991). The role of parental stress in physically abusive families. Child Abuse \& Neglect, 15, 279-291. http://dx.doi.org/10.1016/01452134(91)90072-L

Widom, C. S., \& Maxfield, M. G. (2001). An Update on the" Cycle of Violence." Research in Brief. http://doi.org/10.1037/e528142006-001 